\title{
Matemática financeira: relações entre situações reais e educação para o consumo
}

\section{Financial math: relationships between real situations and education for consumption}

\author{
Neiva Ignês Grando \\ neiva@upf.br
}

Ido José Schneider

ido@proqualificacao.com.br

\begin{abstract}
Resumo
Este artigo faz parte de uma pesquisa cujo objetivo foi analisar a importância e a necessidade da matemática financeira para a vida das pessoas em geral. Apresenta-se uma análise de situações de compras e de financiamentos, identificando os conhecimentos veiculados em cada uma delas e mostrando a necessidade de apropriar-se dos significados dos respectivos conceitos para a tomada de decisões diante das facilidades de crédito proporcionadas pelo comércio e por financeiras, evidenciando o papel da escola na educação financeira.
\end{abstract}

Palavras-chave: Educação financeira. Educação básica. Consumo.

\begin{abstract}
This article is part of a research whose goal was to analyze the importance and need of financial math for people's lives in general. One presents an analysis of situations of purchases and financing, by identifying the conveyed knowledge in each of them and by showing the need to grasp the meanings of the respective concepts before the easiness of credits provided by commerce and financial agencies, rendering evident the role of the school in financial education.
\end{abstract}

Keywords: Financial education. Basic education. Consumption. 


\section{Introdução}

No trabalho Educação Financeira: a Matemática Financeira sob Nova Perspectiva, Santos (2005) teve como objetivo possibilitar o acesso ao conhecimento da matemática financeira a ser utilizado como instrumento para educar financeiramente o jovem e sua família. A importância da educação financeira não está somente na administração das despesas e possibilidades de crédito, mas também no planejamento financeiro para a construção do futuro. Segundo a autora,

é necessário esclarecer o jovem colocando-o a par de alguns aspectos do sistema, levando-o a entender que comprar e vender, acessar serviços bancários e poupar são atos comuns da vida social, mas escondem procedimentos que sugam recursos, muitas vezes eliminando possibilidades futuras de equilíbrio financeiro. (p. 138).

O Guia de Livros Didáticos PNLD 2008, expedido pelo MEC, traz na sua apresentação uma indicação relevante sobre o conteúdo dos livros e sua relação com os diferentes contextos: "Um livro didático deve oferecer informações e explicações sobre o conhecimento matemático que interfere e sofre interferências das práticas sociais do mundo contemporâneo e do passado." (BRASIL, 2007, p. 9).

Por outro lado, encontram-se, atualmente, facilidades cada vez maiores nas compras e empréstimos, especialmente pelo alongamento dos prazos, que resulta em prestações menores, permitindo o acesso de mais pessoas ao consumo. Isso se pode verificar com as inúmeras publicações na mídia, alertando, inclusive, os consumidores sobre os perigos da inadimplência e do endividamento.

Nesse cenário, buscaram-se exemplos de situações reais que pudessem contribuir para melhor esclarecer sobre a necessidade do conhecimento dos conteúdos da matemática financeira por ocasião das compras no crediário e ao assumir um empréstimo ou financiamento. A escolha por essas duas aplicações da matemática (crediário e empréstimos) foi motivada pela importância desses assuntos, tendo em vista a dificuldade que as pessoas e suas famílias têm de controlar seus compromissos financeiros, conforme dados divulgados constantemente pela mídia. Outro fator decisivo para essa opção foram as respostas dadas às questões formuladas aos alunos e professores ${ }^{1}$ nessa pesquisa, pois as maiores preocupações manifestadas por ambos foram em relação às compras a vista e a prazo e a empréstimos e financiamentos.

\footnotetext{
${ }^{1}$ Estudantes de $8^{\mathrm{a}}$ série do ensino fundamental e do $3^{\mathrm{o}}$ ano do ensino médio e professores de matemática da educação básica.
} 
Essas situações reais, comuns na vida das pessoas em geral, em especial nas suas relações de consumo, foram relatadas nos contatos com estabelecimentos comerciais e instituições financeiras de um município localizado na região Norte do estado do Rio Grande do Sul.

\section{Relações entre situações reais e educação para o consumo}

$\mathrm{Na}$ sequência apresentam-se o relato e a análise das informações obtidas em empresas comerciais e de serviços, nas quais se enquadram lojas e instituições financeiras, com o objetivo de visualizar situações em que são utilizados conhecimentos da matemática financeira.

\section{Crediário}

Selecionaram-se três lojas com formas diferentes de atuação: uma que possui rede de lojas, com financeira própria e conveniada $\left(\mathrm{L}_{\mathrm{A}}\right)$; outra rede sem financeira $\left(\mathrm{L}_{\mathrm{B}}\right)$ e uma terceira loja, caracterizada como empresa familiar $\left(\mathrm{L}_{\mathrm{C}}\right)$.

$\mathrm{Na} \mathrm{L}_{\mathrm{A}}$ manteve-se contato com a gerente, que forneceu as mais diversas informações sobre a rede, sua abrangência (região Sul do Brasil), políticas de vendas, taxas de juros, flexibilização nas formas de pagamento, linhas de produtos, entre outras. No estabelecimento simularam-se duas operações de venda a prazo, descritas a seguir.

1. Um aparelho de telefone fixo Embratel por $\mathrm{R} \$ 69,00$ a vista ou em $1+4$ vezes de $\mathrm{R} \$ 15,30$ (produto anunciado com estas condições). Lembra-se que no valor das prestações está incluída uma taxa de abertura de crédito (TAC), de R \$2,99.

Tabela 1 - Simulação: venda aparelho telefônico/crediário.

\begin{tabular}{cccccc}
\hline Simulação & A vista & Entrada & Parcelas & Valor Total & Taxa Juros \\
\hline A & 69,00 & 15,30 & $15,30(4)$ & 76,50 & $5,44 \%$ a.m. \\
B & 69,00 & 25,00 & $12,30(4)$ & 74,20 & $4,62 \%$ a.m. \\
C & 69,00 & 10,00 & $9,00(9)$ & 91,00 & $6,86 \%$ a.m. \\
\hline
\end{tabular}

Fonte: Dados dos pesquisadores, 2008.

Nas simulações pode-se verificar que há alterações significativas nos valores totais a prazo e nas taxas à medida que se altera o valor da entrada. No caso "B", com entrada de 25,00 
consegue-se uma diminuição no valor da prestação, na quantia total paga e também na taxa de juros mensais, isto é, pagam-se menos juros nestas condições. Na situação "C", com uma entrada menor, mas ao mesmo tempo aumentando o prazo para nove parcelas, têm-se um montante maior e um acréscimo na taxa de juros mensais. Para que o consumidor possa compreender as diferentes propostas e calcular os valores, são necessários conhecimentos da matemática financeira, no caso, utilizando conteúdos como juros, porcentagem e regra de três, ou, no mínimo, saber comparar o valor pago a vista com o total a prazo.

2. Um microcomputador PC-TV processador Intel, Pentium Dual Core E2140, 512 MB de memória, HD de 160 GB, gravador de CD e DVD, valor a vista R \$ 1.599,00 ou em 25 parcelas $(1+24)$ de $\mathrm{R}$ \$ 99,90. Nesta operação, além da TAC de R \$ 2,99, poderá ser incluído um seguro prestação de $\mathrm{R} \$ 26,50$ e uma garantia complementar entre 12 e 24 meses, que pode variar de $\mathrm{R} \$ 179,00$ a $\mathrm{R} \$ 329,00$.

Tabela 2 - Simulação: venda microcomputador/crediário.

\begin{tabular}{cccccc}
\hline Simulação & A vista & Entrada & Parcelas & Valor Total & Taxa Juros \\
\hline A & $1.599,00$ & 99,93 & $100,33(24)$ & $2.507,85$ & $4,20 \%$ a.m. \\
B & $1.599,00$ & 500,00 & $73,56(24)$ & $2.265,44$ & $4,20 \%$ a.m. \\
C & $1.599,00$ & 200,00 & $187,90(9)$ & $1.891,10$ & $3,97 \%$ a.m. \\
D & $1.599,00$ & 127,40 & $127,40(24)$ & $3.185,00$ & $5,49 \%$ a.m. \\
\hline
\end{tabular}

Fonte: Dados dos pesquisadores, 2008.

Analisando as diferentes simulações, fica evidente a redução do valor total pago em razão de uma entrada maior e também quando da redução do número de parcelas. Na opção "B”, com uma significativa entrada $(31,3 \%)$ diminuem-se o valor das parcelas e o valor total, apesar de ser mantida a taxa de juros. No caso "C", com entrada de $\mathrm{R} \$ 200,00$ (12,5\%), mas com o restante do pagamento somente em nove parcelas, o montante e a taxa de juros são menores. Pode-se, então, verificar que o aumento do valor da entrada ou a redução do prazo de pagamento traz como vantagem menor desembolso em juros. Por isso, considera-se importante acumular (poupar) algum valor para, quando das compras a prazo, poder dar uma entrada de maior valor. Na hipótese da simulação " $D$ " foram incluídos o seguro prestação, no valor de $\mathrm{R} \$ 26,50$, e a garantia complementar para o produto em até 12 meses, de $\mathrm{R} \$ 179,00$. Com isso, alteraram-se significativamente o valor total e a taxa, porque na base de cálculo 
inicial de $\mathrm{R} \$ 1.599,00$ são acrescentados esses valores, partindo-se de uma dívida de $\mathrm{R} \$$ $1.804,50$.

A rede de lojas em questão, além da variada linha de produtos que comercializa, oferece empréstimo consignado para aposentados e pensionistas do INSS e crédito pessoal, de acordo com um limite aprovado com base nos dados cadastrais do cliente. Quanto à primeira modalidade, o valor varia conforme os rendimentos da aposentadoria e as taxas de juros ficam entre $1 \%$ e $2,38 \%$ ao mês, dependendo do prazo fixado para os retornos, geralmente entre seis e trinta e seis meses. Contudo, os tomadores de empréstimos deste tipo precisam estar atentos quanto ao anúncio sobre as taxas - "a partir de $1 \%$ ao mês" - porque esta taxa só vale para prazos menores (seis meses). Sobre a segunda linha de crédito para pessoas físicas, o crédito pessoal, pode-se verificar que se trata de um limite semelhante ao cheque especial dos bancos, incluído no total do limite de crédito do cliente (para compra e empréstimo em dinheiro). Apresenta-se a seguir um exemplo de empréstimo de $\mathrm{R} \$ 500,00$, que inclui a TAC de $\mathrm{R} \$$ 15,76 e seguro por invalidez ou morte, no valor de $\mathrm{R} \$ 28,30$.

Tabela 3 - Simulação: empréstimo pessoal.

\begin{tabular}{cccccc}
\hline Simulação & Empréstimo & Tac+seguro & Parcelas & Valor Total & Taxa Juros \\
\hline A & 500,00 & 44,06 & $98,91(8)$ & 791,28 & $9,17 \%$ a.m. \\
B & 500,00 & 44,06 & $81,47(12)$ & 977,64 & $10,41 \%$ a.m. \\
C & 500,00 & 44,06 & $136,26(5)$ & 681,32 & $8,00 \%$ a.m. \\
\hline
\end{tabular}

Fonte: Dados dos pesquisadores, 2008.

Como se observa, a incidência de taxas de juros maiores para o crédito pessoal é justificada pela gerente da loja com o alto risco de inadimplência e a inexistência de garantias vinculadas aos empréstimos. Ela também informou que, em geral, não são emprestados valores muito expressivos e que atendem mais a pessoas com renda mensal de até dez salários mínimos ( $\mathrm{R} \$$ $3.800,00)$.

Segundo Soares (2006), "esses consumidores, agrupados nas classes C (renda de cinco a dez salários mínimos), D (de dois a cinco mínimos) e E (menos de dois mínimos), têm sido a grande alavanca do aumento recente da oferta de crédito.” (p. 99). A autora apresenta uma fundamentação deste direcionamento do crédito para as pessoas destas faixas de renda, afirmando que "seu poder aquisitivo melhorou muito nos últimos dez anos, período em que o 
salário mínimo cresceu $329 \%$, contra uma inflação de $147 \%$ e são responsáveis por $71 \%$ do consumo no país.” (p. 103).

$\mathrm{Na}$ visita à $\mathrm{L}_{\mathrm{B}}$, o gerente colocou-se à disposição para prestar as informações necessárias, como a de que a rede opera com capital próprio na sua carteira de crediário e que a taxa de juro cobrada não ultrapassa $2 \%$ ao mês, com prazos máximos de até 10 vezes $(1+9)$. A empresa considera a taxa de $2 \%$ como margem (ganho) por estar embutida no preço final da venda a prazo. Nas vendas a vista opera com descontos de 10\% (no máximo). Nas negociações com os clientes, mesmo com produtos anunciados (nas promoções), os vendedores têm flexibilidade sobre os prazos e taxas, dentro dos limites da política adotada pela rede de lojas. Sobre eventuais atrasos nos pagamentos das parcelas, estes são negociados com a gerência, procurando-se conciliar os interesses das partes, se possível cobrando juros um pouco superiores do que aqueles cobrados no momento da venda normal.

Simula-se agora uma operação de venda de uma TV 29" CCE, a vista por R \$ 599,00 ou em $1+12$ parcelas de $\mathrm{R}$ 59,90, constante no folder promocional do mês (dezembro/2007).

Tabela 4 - Simulação: venda produto anunciado em folder/crediário.

\begin{tabular}{cccccc}
\hline Simulação & A vista & Entrada & Parcelas & Valor Total & Taxa Juros \\
\hline A & 599,00 & 59,90 & $59,90(12)$ & 778,70 & $4,73 \%$ a.m. \\
B & 599,00 & 120,00 & $50,98(12)$ & 731,76 & $3,98 \%$ a.m. \\
\hline
\end{tabular}

Fonte: Dados dos pesquisadores, 2008.

Novamente se verifica que a entrada maior, mantendo o mesmo prazo, gera prestações menores, um montante menor, taxa menor, representando, pois, economia de juros na opção "B".

Nas promoções anunciadas com prazos superiores a dez meses constata-se que as taxas de juros cobradas divergem das declaradas pelo gerente da loja. Para isso, a justificativa dada por ele é de que os parcelamentos superiores a dez meses são praticados apenas com algumas linhas de produtos, no caso, o juro cobrado acompanha as taxas do comércio em geral.

Sabe-se que as propagandas sobre o crediário, em geral, procuram dar destaque maior ao preço a vista e ao valor da prestação, sendo as demais informações menos realçadas. Assim, o anúncio apresentado a seguir mostra como as pessoas podem cair nas armadilhas do crediário. 


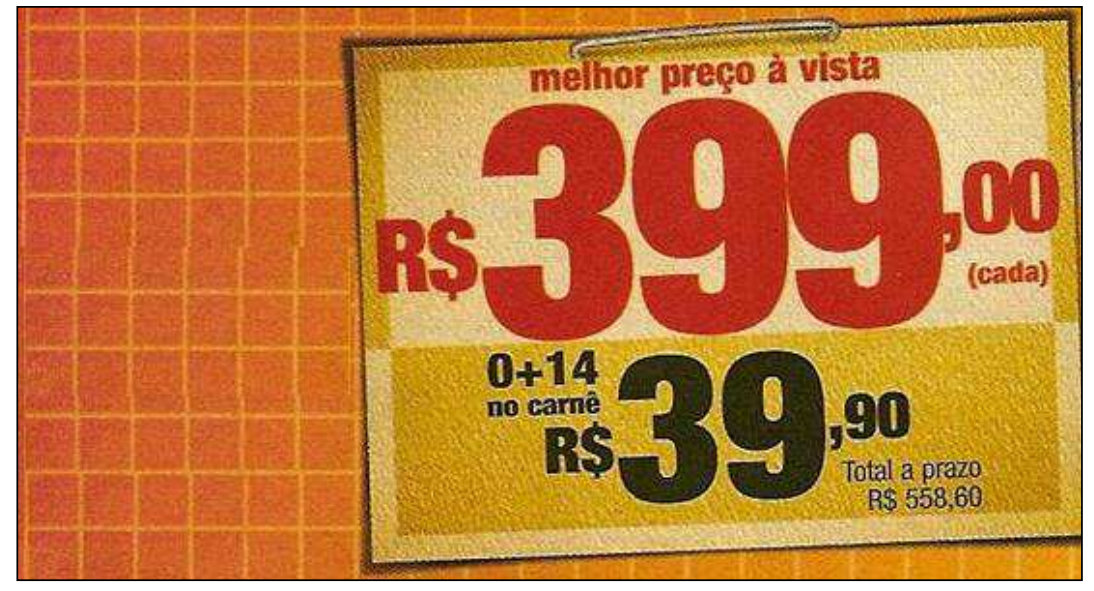

Figura 1: Anúncio de crediário.

Vê-se que o valor da parcela guarda uma proporção de décima parte em relação ao valor a vista, mas as parcelas não são em número de dez. Além disso, nesse tipo de propaganda, a taxa de juro normalmente se encontra no rodapé da última página do folder promocional.

A $\mathrm{L}_{\mathrm{C}}$, por ser uma empresa familiar, apresenta uma forma de crediário e de negociação nas vendas com características próprias. Segundo o proprietário, "aqui cada caso é um caso", mostrando maior flexibilidade nos preços e prazos do que as demais empresas com grandes redes de lojas. Por isso, as vendedoras têm autonomia de chegar até $20 \%$ de desconto nas vendas a vista. $\mathrm{Na}$ modalidade a prazo, não se fala em juros, mas em preço de venda, calculado com base na formação do preço de custo, acrescido da margem de ganho (lucro). No caso de atraso nas prestações, está estabelecido um percentual de 3\% de juros ao mês, mas sempre havendo a possibilidade de negociar uma redução com o proprietário.

Uma funcionária da loja elaborou uma situação ilustrativa de como pode ocorrer uma negociação na venda a prazo, flexionando o valor da entrada, como se representa na tabela a seguir.

Tabela 5 - Simulação: crediário direto (sem financeira).

\begin{tabular}{ccccc}
\hline Simulação & Valor Produto & Entrada & Parcelas & Valor Final \\
\hline A (a vista) & $1.000,00$ & - & - & 800,00 \\
B (a prazo) & $1.000,00$ & 200,00 & $200,00(4)$ & $1.000,00$ \\
C (a prazo) & $1.000,00$ & 400,00 & $125,00(4)$ & 900,00 \\
\hline
\end{tabular}

Fonte: Dados dos pesquisadores, 2008. 
No primeiro caso (A), venda a vista, concedeu-se um desconto de $20 \%$ sobre o valor do produto, resultando num valor final pago de R\$ 800,00. Na opção "B" ocorreu a venda normal a prazo, sem alteração dos valores das parcelas, e o desconto não concedido pode ser considerado como a margem de ganho (juro). No terceiro exemplo, já com uma entrada maior, houve a possibilidade de reduzir o valor de cada parcela restante e, assim, chegar a um valor final menor (equivalente a um desconto de $10 \%$ sobre o valor do produto vendido nessas condições).

Nos contatos mantidos com os diferentes tipos de estabelecimentos comerciais, ou seja, nas formas diversas de negociar com seus clientes e na apresentação promocional de seus produtos, observaram-se algumas características comuns a esse segmento de atividade. Todos afirmaram, por exemplo, que preferem vender mais na modalidade a prazo, citando alguns motivos: ganho financeiro maior (com a inflação baixa), o cliente retorna à loja para pagar as parcelas, e na venda a vista há uma redução na margem (ganho ou lucro). De outra parte, também para o consumidor importa mais o valor da prestação do que saber qual é a taxa de juros que está sendo cobrada; inclusive, o próprio comerciante muitas vezes alonga o prazo, diminuindo o valor da parcela, para poder realizar a venda.

\section{Empréstimos ou financiamentos}

Para apresentar situações reais de empréstimos ou financiamentos, optou-se por três situações diferentes, envolvendo financeiras e bancos: financiamento de automóvel em bancos, financiamento de moto por uma financeira e empréstimo consignado. Escolheram-se esses tipos por estarem, na atualidade, mais em evidência, segundo os próprios atendentes das instituições de crédito visitadas.

Na primeira situação de aquisição de um automóvel marca Chevrolet, modelo Vectra, ano 1997, avaliado em R $\$ 20.000,00$, cujo comprador necessitava de $\mathrm{R} \$ 7.000,00$ para completar o valor total do veículo. Neste caso uma revenda de veículos usados efetuou a intermediação auxiliando na busca da melhor opção de financiamento na rede bancária local. Assim, obtiveram-se as informações constantes na tabela a seguir: 
Tabela 6 - Condições: financiamento de automóvel.

\begin{tabular}{ccrccc}
\hline Banco & Taxa de Juro & TAC & Prestação & Total Final & Taxa Efetiva \\
\hline A & $1,52 \%$ a.m. & 600,00 & $275,67(36 \mathrm{x})$ & $9.924,12$ & $2,02 \%$ a.m. \\
B & $1,62 \%$ a.m. & 200,00 & $273,53(36 \mathrm{x})$ & $9.847,08$ & $1,98 \%$ a.m. \\
C & $1,70 \%$ a.m. & 0,00 & $261,57(36 \mathrm{x})$ & $9.416,52$ & $1,70 \%$ a.m. \\
\hline
\end{tabular}

Fonte: Dados dos pesquisadores, 2008.

Como se observa, ao serem comparadas as taxas e prestações, fica-se, num primeiro momento, até surpreso, porque a maior taxa nominal resultou na menor prestação mensal, contudo numa operação de crédito não se pode analisar apenas um dos dados informados. Assim é que logo na segunda coluna já se depara com a taxa de abertura de crédito (TAC), que está sendo incluída no valor do financiamento, alterando a base de cálculo inicial, isto é, a dívida inicial do comprador passa a ser de $\mathrm{R} \$ 7.600,00$ (A) e de $R \$ 7.200,00$ (B), influenciando diretamente na taxa e no valor dos juros pagos. No Banco (C) não há a cobrança da TAC, mas exige-se um depósito de R $\$$ 140,00, uma espécie de seguro-garantia sobre o crédito, que no final do financiamento poderá ser resgatado, com o valor corrigido; ainda assim, permanece sendo a opção mais vantajosa.

Uma segunda ocorrência de financiamento, no caso uma moto Honda Biz 125 nova, foi uma proposta trazida por uma aluna que tinha dúvidas quanto à taxa de juros desta operação de crédito. $\mathrm{O}$ valor a vista seria de $\mathrm{R} \$ 5.000,00$ ou financiado em 36 parcelas de $\mathrm{R} \$ 235,00$, com uma taxa de juros de 2,48\% ao mês. Para melhor visualização, demonstram-se os valores e condições na tabela a seguir.

Tabela 7 - Financiamento de moto.

\begin{tabular}{cccccc}
\hline Financeira & A vista & Parcelas & Total Final & Tx. Nominal & Tx.Efetiva \\
\hline $\mathrm{X}$ & $5.000,00$ & 235,00 & $8.460,00$ & $2,48 \%$ a.m. & $3,17 \%$ a.m. \\
\hline
\end{tabular}

Fonte: Dados dos pesquisadores, 2008.

É de se observar que a financeira que apresentou a proposta até duvidou dos cálculos que se realizou quando a pretendente do financiamento alegou que havia uma diferença de $0,69 \%$ ao mês na taxa de juros. Ao indagar o vendedor sobre alguma taxa que poderia estar sendo cobrada, confirmou-se que a divergência nos índices estava na inclusão da TAC, no valor de $\mathrm{R} \$ 550,00$, o que acaba aumentando o valor de cada parcela e, consequentemente, também a 
taxa de juros mensais. Se o comprador pagasse esta despesa no ato da compra, os números estariam corretos; porém, geralmente, este valor é embutido nas prestações, sob a alegação de que altera muito pouco o valor de cada parcela. Portanto, o comprador precisa estar atento quando financia qualquer bem, exigindo o esclarecimento de todas as dúvidas e, se for o caso, como nesta proposta, solicitando orientação de um especialista na área financeira.

A terceira modalidade de empréstimo que se exemplifica denomina-se "empréstimo consignado", por estar vinculado à folha de pagamento das empresas ou ao benefício recebido para aposentados e pensionistas. O objetivo principal de se trazer esse exemplo não está nos cálculos das taxas e valores das parcelas, e, sim, na forma como esta modalidade de empréstimo é apresentada nos anúncios. Por exemplo, encontra-se em vários locais, como em financeiras, lotéricas e no próprio banco contatado, a seguinte frase: "Empréstimos a partir de 0,92\% ao mês...a menor taxa do mercado"! Todavia, não está claro que esta taxa é somente para o prazo de seis vezes (seis pagamentos iguais). Como confirmado pelos próprios atendentes desses estabelecimentos, a maioria dos que buscam o crédito parcela o pagamento em 36 vezes, com uma taxa de 2,30\% ao mês. Existem outras taxas intermediárias, como a de 1,69\% a.m., para 12 meses, e de 2,16\% a.m., para 24 parcelas de reposição.

Preocupado com o crescente endividamento dos aposentados e pensionistas, o governo federal autorizou um alongamento no prazo dessa modalidade de empréstimos para até sessenta meses, com o objetivo de aliviar o orçamento mensal dos devedores pela diminuição do valor das parcelas. Criaram-se, então, mais duas faixas de crédito: uma com o pagamento em 48 meses, a uma taxa de $2,45 \%$ ao mês, e a outra com o prazo máximo de até 60 meses, ficando a taxa de juros em $2,60 \%$ ao mês.

Entretanto, o que aparenta ter sido um benefício aos mutuários trouxe um ônus ainda maior para os endividados, porque o prazo mais longo aumenta o custo do empréstimo com a concomitante elevação da taxa de juros. Essa afirmação está evidenciada em dados retirados de uma tabela obtida em um banco, em que constam várias opções de valores, prazos e taxas, com um caso específico de cobrança das parcelas na folha de pagamento do INSS quanto a empréstimo consignado. Ao serem comparadas as taxas convertidas para períodos anuais, verifica-se que a taxa de $0,92 \%$ ao mês equivale a $11,616 \%$ ao ano pelo prazo de até seis meses, ao passo que a taxa mensal de 2,30\% corresponde a 31,373\% ao ano, quando o prazo for de 36 meses. Com o novo prazo concedido (60 meses), a uma taxa mensal de juros de $2,60 \%$, a correspondente anual passa a ser de 36,072\%, indicando uma elevação de 4,699\% a cada ano. Para avaliar o que pode representar essa diferença na taxa, faz-se a comparação com 
a inflação anual prevista no Brasil (2008), de 4,5\%, isto é, considerando somente o percentual no aumento da taxa de juros com este novo prazo, ele é superior à taxa inflacionária do mesmo período.

Para que as pessoas, em geral, possam compreender as diferentes propostas tanto nas compras a prazo como nos financiamentos, sabendo efetuar os cálculos corretamente e o quanto estão pagando de juro ou recebendo de desconto, no caso da compra a vista, o conhecimento dos conteúdos da matemática financeira é imprescindível numa relação de negócios entre vendedor/comprador ou credor/devedor. Destacam-se a importância e a necessidade de uma educação financeira para o consumo, com o fim de compreender claramente o significado do que se está assumindo numa compra a prazo ou nos empréstimos. Só assim se pode realizar uma operação consciente, sem haver dúvidas entre os sujeitos envolvidos sobre as condições acordadas.

\section{Considerações finais}

A análise das situações dos diferentes contextos revela a importância e a necessidade dos conceitos de matemática financeira para realizar uma compra consciente, ou contrair uma dívida por empréstimo, sabendo quanto efetivamente será pago.

Santos manifesta sua opinião sobre os motivos que podem levar as pessoas a endividar-se, afirmando que "o endividamento de grande parte da população é um problema muitas vezes gerado pela impossibilidade de efetuar cálculos e agir com consciência diante das inúmeras ofertas do comércio e do crédito." (2005, p. 67).

Segundo informações dos gerentes das lojas contatadas, os consumidores, em geral, preocupam-se somente com o valor da parcela, se caberá ou não no seu orçamento mensal, no momento da compra. Esta postura das pessoas evidencia a falta de conhecimento dos valores efetivos que estão sendo cobrados. Certamente, se soubessem calcular a taxa de juros e verificar o valor total a ser pago até o final do prazo, teriam a possibilidade de efetuar uma compra mais consciente, negociando melhores condições; quem sabe, inclusive, optariam por oferecer uma entrada maior, com a consequente redução dos juros, evitando endividamentos. Os estabelecimentos comerciais, em especial as grandes redes que já estão informatizadas, ao cadastrar o cliente com as informações fornecidas e comprovadas, calculam um limite individual ou familiar para compras a prazo. Por isso, em algumas ocasiões, para possibilitar 
uma nova venda aumentam o prazo, consequentemente baixando o valor da prestação e, assim, ficando dentro dos limites observados.

Lopes, referindo-se ao procedimento adotado pelos lojistas em relação àqueles consumidores de baixo poder aquisitivo, que também são público-alvo para suas vendas, afirma que:

as grandes lojas voltadas para os consumidores de baixa renda geralmente direcionam suas campanhas publicitárias no valor da prestação. Pois este tipo de consumidor infelizmente, por necessidade, leva em consideração apenas o valor da prestação, e não o valor final do bem que chega a ser duas vezes. (2005, p. 65).

Uma observação que se deve fazer é em relação às taxas de juros cobradas, uma vez que a maioria das pessoas não questiona os percentuais de acréscimo no momento da compra a prazo. Para calcular a taxa exata ou efetiva necessita-se do conhecimento de matemática financeira, com uso de fórmula ou de uma calculadora financeira, incluindo corretamente os dados mínimos, como o preço a vista, se a compra é com ou sem entrada, o valor da prestação e o número de parcelas, para se obter a taxa percentual de juro mensal que está sendo cobrada.

No entanto, conforme salientam Grando e Schneider, "para apropriar-se dos significados que compõem o sistema de conceitos 'juros' é necessário que as pessoas participem de um processo de ensino e de aprendizagem sistemático, formal." (2010, p. 59).

Também é relevante saber que, no caso das compras a prazo, tanto no sistema de crediário direto nas lojas como pelas financeiras, quanto mais longo o prazo, mais aumenta a taxa de juros, corroborando a afirmação de Borges de que "os juros crescem com o aumento do número de parcelas. Por isso, quanto maior o número de prestações, mais caro fica o produto. Em menos parcelas, a taxa de juros é menor.” (1999, p. 57). Os comerciantes justificam esse procedimento pelo risco maior de inadimplência, comportamento do mercado, incerteza em relação ao futuro por envolver um período de tempo mais longo, ou, ainda, perda de emprego ou diminuição da renda do devedor.

Pode-se verificar, então, que nas compras pelo crediário ocorre muitas vezes uma negociação, um embate entre o vendedor e o comprador (consumidor), com ampla vantagem do primeiro. Para o vendedor, as lojas oportunizam cursos, treinamentos, motivação para atingir as metas; como parte do seu salário, da sua sobrevivência, depende do seu desempenho nas vendas, ele tenta ao máximo convencer o comprador dos benefícios dos produtos e o preço passa a ser um detalhe no final. Do outro lado está o consumidor, normalmente já pressionado e bombardeado pela propaganda da mídia, mais fragilizado porque está despreparado para negociar e, em geral, não teve uma educação financeira na escola que lhe proporcionasse 
condições de questionar os valores e taxas propostos. Ainda, não raras vezes, levado pelo consumismo, ele adquire produtos por impulso, pela oferta ou liquidação, não refletindo sobre a real necessidade daquele produto.

Quanto aos empréstimos e financiamentos, atualmente se encontram facilidades na sua obtenção, tanto para retirada de dinheiro (mais relacionado com os empréstimos) como para a aquisição de bens (no caso, os financiamentos). Com uma proposta de crédito fácil anunciamse parcelamentos em até 36 vezes para dinheiro e prazos de até oitenta vezes para veículos, por exemplo.

Optou-se por aprofundar as análises sobre algumas modalidades de crédito, considerando as preocupações manifestadas por alunos e professores e o que a mídia tem destacado como as operações mais procuradas pelos consumidores, ou seja, financiamentos de veículos, créditos consignados e empréstimos pessoais. Há muitas ofertas e variadas opções tanto nos prazos como nas taxas de juros e em outros encargos, que podem confundir os compradores. As promoções são anunciadas procurando sempre destacar a facilidade, a agilidade, a ausência de burocracia para liberação dos valores; por isso, o consumidor precisa estar atento para não cair em armadilhas.

Nos financiamentos para veículos, automóveis e motocicletas, por exemplo, analisaram-se diversas opções oferecidas aos compradores, como com ou sem entrada, valor da TAC e seguro garantia, porque influem diretamente no valor da prestação e no percentual da taxa de juros. Os vendedores alegam e tentam convencer as pessoas de que essas taxas alteram em pouco o valor da parcela mensal, mas o consumidor mais preparado, que sabe fazer os cálculos matemáticos, logo percebe que a taxa de juros cobrada altera-se significativamente com a inclusão desses encargos no valor financiado. Por isso, no momento de contratar um financiamento, o mutuário deve obter todas as informações sobre valores, prazos e taxas, por exemplo. As pessoas, geralmente, não sabem que isso é um direito que elas têm. Recentemente, o Banco Central do Brasil baixou uma resolução ( ${ }^{\circ} 3.517$, de 6 de dezembro de 2007) que obriga as instituições financeiras a informar e divulgar aos clientes as condições estabelecidas nos contratos. Com a vigência desse dispositivo legal, as financeiras estão obrigadas a fornecer previamente à contratação de operações de crédito com pessoas físicas todas as informações e o custo total da operação. Porém, de nada adianta a existência da lei se as pessoas não compreenderem o significado dessas informações e o impacto no seu orçamento pessoal. 
Outra modalidade de crédito analisada foi o crédito pessoal, também chamada de "empréstimo pessoal", atualmente oferecida diretamente por financeiras ou pelas grandes redes de lojas. Como se trata de situações emergenciais ou casos urgentes, muitas vezes para liquidar outras dívidas já vencidas, as instituições cobram taxas maiores, pelo risco maior de inadimplência, incluindo normalmente seguro garantia do crédito e de vida para o devedor. Com isso, as taxas de juros elevam-se consideravelmente, chegando, em muitos casos, a mais de $10 \%$ ao mês. De acordo com Ribeiro, esta ideia do dinheiro fácil para quem já está endividado tem um custo mais elevado e pode levar a situações ainda mais graves.

A oferta de dinheiro nas ruas é uma tentação para os incautos. Com a promessa de crédito fácil e ágil, o dinheiro é emprestado a juros exorbitantes, que chegam a até $15 \%$ ao mês. Com isso, a dívida chega a quadruplicar ao fim de um ano. Como normalmente quem acessa esse crédito são pessoas que não tem mais limites em bancos, por já estarem endividadas, o risco de levar a situação de dívida aos extremos é muito alto. (2007, p. 20).

$\mathrm{Na}$ análise sobre o crédito pessoal, entende-se que o consumidor deve fazer uso desta linha de crédito somente em casos extremos e, se possível, não alongar demais os prazos, como se viu na simulação feita nesta pesquisa, em que se constata claramente a grande variação na taxa de juros em vista do prazo do empréstimo. No caso específico de cinco parcelas, a taxa fica em $8 \%$ ao mês e, para reposição em doze prestações, o percentual dos juros chega a $10,41 \%$ mensal.

Ainda quanto ao crédito pessoal, as pessoas precisam ter a certeza de que é a única, ou a última opção a recorrer para saldar determinada dívida assumida, pois existem no mercado financeiro outras modalidades de empréstimos com taxas menores, como é o caso do financiamento de veículo próprio, em que a instituição financeira adianta dinheiro vinculando como garantia o bem financiado até a liquidação das prestações. Uma saída menos onerosa é também o empréstimo consignado, descontado diretamente do salário ou do benefício do tomador, o que reduz o risco para os bancos, podendo, assim, cobrar taxas menores. Infere-se, portanto, que as pessoas devem buscar todas as informações e, se for o caso, recorrer a um especialista em finanças pessoais para decidir pela melhor opção ou a mais adequada para o seu caso naquele momento.

Optou-se também pela análise do empréstimo consignado para os aposentados e pensionistas, por apresentar-se muitas vezes como a solução financeira para as famílias, porém a forma como são anunciadas as condições deixa dúvidas, especialmente quanto às taxas de juros cobradas. Por isso, destacou-se um anúncio que informava uma taxa a partir de $0,92 \%$ ao mês. 
Todavia, verifica-se que esta taxa é utilizada somente para o prazo de até seis meses. Como a maioria das pessoas que busca este tipo de crédito solicita prazos maiores, como 24 ou até 36 meses, as taxas podem chegar a 2,30\% ao mês. Esses percentuais são elevados se levado em conta o retorno garantido para as instituições financeiras pelo débito automático na folha de pagamento do INSS; ainda, ao ser comparado com a remuneração paga pelo dinheiro aplicado nos bancos, em poupança, por exemplo, em média $0,65 \%$ ao mês, ou mesmo para valores expressivos em renda fixa, dificilmente o rendimento ultrapassará $1 \%$ ao mês.

Constatando a necessidade dos conteúdos de matemática financeira para a tomada de decisões apropriadas nas relações de consumo e do mundo do trabalho, alerta-se para o importante papel da escola na preparação dos alunos para a vida no seu contexto social e econômico, como cidadãos consumidores mais conscientes, capazes não só de controlar seus gastos, mas, também, de planejar seu futuro, sabendo administrar seus recursos financeiros.

\section{Referências}

BORGES, L. Salve seu bolso: o mais completo guia para antes, durante e depois da compra. São Paulo: Petrópolis, 1999.

BRASIL. Guia de livros didáticos PNLD 2008: matemática: séries/anos finais do ensino fundamental. Secretaria de Educação Básica. Brasília: MEC, 2007.

GRANDO, N. I.; SCHNEIDER, I. J. Matemática financeira: alguns elementos históricos e contemporâneos. Zetetiké, Campinas, v. 18, n. 33, p. 43-62, jan./jun. 2010.

LOPES, E. A. B. Do economês para o português: seu consultor de bolso. Porto Alegre: Corag, 2005.

RIBEIRO, S. Ano-novo, finanças novas. Zero Hora, Porto Alegre, 30 dez, 2007.

SANTOS, G. L. da C. Educação financeira: a matemática financeira sob nova perspectiva. 2005. Dissertação (Mestrado em Educação para a Ciência) - Faculdade de Ciências, Universidade Estadual Paulista, Bauru, 2005.

SOARES, L. O show do crediário. Veja, São Paulo, n. 1953, abr., p. 98-105, 2006. 